\title{
CARACTERIZAÇÃO FÍSICO-QUÍMICA DA PALHA DE CANA DE AÇÚCAR: UMA REVISÃO DE LITERATURA
}

\author{
M. M. SANTOS ${ }^{1}$, T. T. FRANCO ${ }^{1}$ e M. D. BERNI ${ }^{2}$ \\ ${ }^{1}$ Universidade Estadual de Campinas, Faculdade de Engenharia Química \\ ${ }^{2}$ NIPE, Universidade Estadual de Campinas \\ E-mail para contato: ma.mugnol@gmail.com
}

\begin{abstract}
RESUMO - A cadeia produtiva da cana de açúcar tem focado grande interesse no aproveitamento integral dos seus principais subprodutos: a palha e o bagaço. Atualmente a palha não está consolidada como combustível ou alternativa para etanol de segunda geração. Este trabalho teve como objetivo levantar o estado da arte quanto à caracterização físico-química da palha de cana de açúcar. Com extensa pesquisa bibliográfica foram levantados, estudados e analisados informações de caracterização elementar físico-química disponíveis na literatura, sobretudo em periódicos indexados. De uma forma geral, os estudos disponíveis mostram os dados e informações bastante aleatórios sem guardar aderência entre os mesmos, ou seja, apresentam-se composição e comportamentos diferentes para cada um dos componentes da palha baseados. Neste trabalho foi aprofundada a análise dos resultados de teor de cinzas, comparando parâmetros para encontrar a origem da variação entre seus resultados. Baseado nas pesquisas a que se teve acesso, pode-se afirmar que ainda é necessário reproduzir esse estudo para as demais análises e resultados encontrados durante o levantamento de dados para assegurar a palha de cana de açúcar como uma possível biomassa para a produção de biocombustíveis de segunda geração ou como combustível térmico.
\end{abstract}

\section{INTRODUÇÃO}

Devido à sua grande produção agrícola o Brasil dispõe de uma quantidade considerável de resíduos agrícolas e agroindustriais cujo bioprocessamento pode ser de grande interesse econômico e social. Entre estes resíduos, o mais expressivo em quantidade é a palha gerada na fase agrícola pós-colheita da cana de açúcar, pois para cada tonelada de cana são produzidas cerca de $145 \mathrm{~kg}$ base seca de sacarose, $140 \mathrm{~kg}$ base seca de bagaço e $140 \mathrm{~kg}$ base seca palha (Almeida, 2008). A palha consiste na ponteira e nas folhas da planta da cana-deaçúcar, com grande potencial de geração de produtos com alto valor agregado, uma vez que cerca de $30 \%$ da energia total da planta está contida neste material (Almeida, 2008). Com a introdução de legislação ambiental rígida que proíbe qualquer queima deste material no Estado de São Paulo, a partir de 2015 a palha está se tornando mais disponível.

A palha pode ser utilizada como insumo em biorrefinarias instaladas nas próprias usinas e destilarias na produção de materiais de maior valor agregado tais como resinas e 

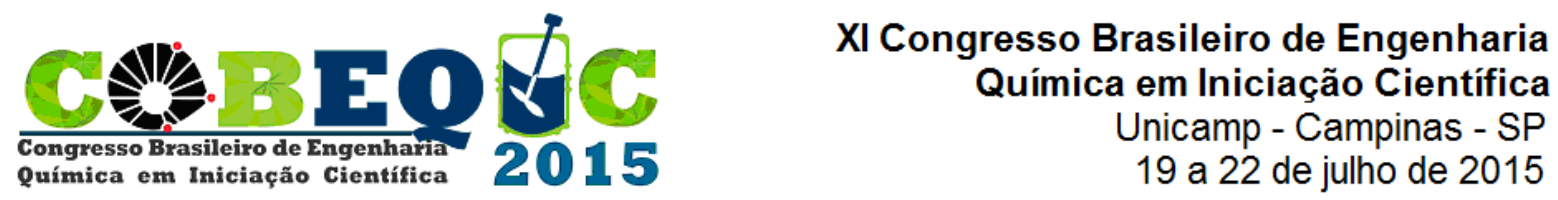

filmes de polímeros, plásticos recicláveis, dispersantes, floculantes, além de outros usos mais tradicionais, como na produção de papel e na geração de energia elétrica e térmica renovável.

O levantamento de dados sobre as características físico-químicas da palha da cana-deaçúcar é de extrema importância para facilitar análise de viabilidade de uso das tecnologias disponíveis para o aproveitamento deste insumo.

\section{METODOLOGIA}

As atividades foram focadas no levantamento de resultados obtidos por diferentes autores para análises físico-químicas da palha da cana-de-açúcar. A principal fonte de dados foi o banco de publicações do ISI Web of Knowledge, denominado Web of Science, acessada via portal de periódicos da Coordenação de Aperfeiçoamento de Pessoal de Nível Superior (CAPES) (www.periodicos.capes.gov.br), a partir de parâmetros de busca tendo como chave: biorrefinaria, bioenergía, bioprodutos, materiais lignocelulósicos e eficiência energética. Sites de organizações representativas do setor de açúcar e bioetanol, como a UNICA, também foram consultados. A partir dos trabalhos aos quais se teve acesso foram elaboradas tabelas comparativas das análises, contendo os resultados das mesmas, local de onde a amostra é proveniente (quando disponível) assim como as metodologias utilizadas por cada autor (quando citadas). Realizou-se a comparação dos métodos utilizados pelos autores, mais especificamente para a determinação do teor de cinzas da palha de cana de açúcar.

\section{ESTADO DA ARTE DA CARACTERIZAÇÃO DE BIOMASSA}

O presente trabalho focou na construção de um banco de dados contendo resultados da caracterização da palha de cana-de-açúcar a partir de trabalhos e artigos indexados aos quais se teve acesso. As análises estudadas e o número de trabalhos encontrados para cada estão reunidos na Tabela 1 que segue abaixo.

Tabela 1 - Análises estudadas no presente trabalho e número de publicações estudadas para cada

\begin{tabular}{|c|c|}
\hline Análise & Número de publicações estudadas \\
\hline Cinzas & 7 \\
\hline Umidade & 2 \\
\hline Extrativos & 3 \\
\hline Voláteis & 3 \\
\hline Carbono Fixo & 3 \\
\hline Poder Calorífico & 4 \\
\hline Lignina & 6 \\
\hline Análise Elementar & 4 \\
\hline
\end{tabular}


É necessário ressaltar que a origem das amostras de palha de cana-de-açúcar assim como as variedades da planta são diferentes entre si, sendo essa uma das possíveis fontes das diferenças encontradas nos resultados das análises. Na Tabela 2 estão descritas a origem de cada amostra de cada autor que especificou a mesma em seu trabalho.

Tabela 2 - Origem das amostras de palha de cana-de-açúcar da literatura analisada

\begin{tabular}{|c|c|}
\hline Referência & Origem da Amostra \\
\hline MARABEZI, K (2009) & Usina Ipiranga, São Carlos - SP (2007) \\
\hline GEORGES, F. (2011) & Empresa Dom Braga, Dois Irmãos - RS (2011) \\
\hline MIRANDA, I.C. (2009) & Região de Campinas - SP (2008) \\
\hline PITARELO, A.P. (2007) & Indústria Sucroalcooeira Melhoramentos S/A, Jussara - PR \\
\hline & $\begin{array}{c}\text { Variedade UFV/RIDESA RB867515 (5 meses de idade). } \\
\text { Centro de Pesquisa e Experimentação de Cana-de-açúcar do } \\
\text { Departamento de Fitotecnia da Universidade Federal de } \\
\text { Viçosa - MG (2010) }\end{array}$ \\
\hline SEYE, O. et al (2000) & Não especificada \\
\hline PAULA, L.E.R. et al (2011) & Lavras - MG (2011) \\
\hline SUÁREZ, J.A. et al (2000) & Saccharum officinarum \\
\hline
\end{tabular}

Para análise mais aprofundada e comparativa entre os resultados, escolheu-se a análise de teor de cinzas, pois altos teores desse componente interferem na eficiência de processos realizados na palha para a sua utilização como fonte energética (Pitarelo, 2007). Observam-se na Tabela 3 os resultados obtidos por diferentes autores para o teor de cinzas em base seca da palha da cana de açúcar.

Tabela 3 - Teor de cinzas com base na massa seca

\begin{tabular}{|c|c|c|c|}
\hline$\%$ & \pm & Método & Referência \\
\hline 7,91 & 0,02 & TAPPI 211 om-93 & CARVALHO, D.M. (2012) \\
\hline 7,00 & - & ASTM E1534-93 & SEYE, O. et al (2000) \\
\hline 11,70 & - & TAPPI T221 om-93 & PITARELO, A.P. (2007) \\
\hline 4,97 & - & TAPPI T211 om-93 & MARABEZI, K. (2009) \\
\hline 4,32 & - & M11/77 ABTCP 1974; NBR 8112 ABNT & PAULA, L.E.R. et al (2011) \\
\hline 12,48 & - & TAPPI T211 om-93 & GEORGES, F. (2011) \\
\hline 9,30 & - & ASTM D $1762-82$ & SUÁREZ, J.A. et al (2000) \\
\hline
\end{tabular}


Nota-se que o resultado varia de 4,32\% a 12,48\%. A proveniência da amostra usada por cada autor é uma das possíveis explicações para a variação dos resultados obtidos. Segundo Almeida (2008) teores elevados de cinzas na palha da cana-de-açúcar podem ser decorrentes do manuseio da palha durante a colheita e o transporte, sendo esse outro possível fator que contribuiu para a obtenção de valores divergentes de cinzas.

Outra possível explicação para esses resultados seria o uso de diferentes metodologias, portanto a partir das metodologias apresentadas disponíveis a acesso construiu-se a Tabela 4 para efeitos comparativos.

Tabela 4 - Principais definições dos métodos utilizados para determinação do teor de cinzas

\begin{tabular}{|c|c|c|c|c|c|}
\hline Método & $\begin{array}{c}\text { Tempera- } \\
\text { tura }\left({ }^{\mathbf{0}} \mathbf{C}\right)\end{array}$ & Tempo & $\begin{array}{c}\text { Massa de } \\
\text { Amostra/ } \\
\text { Caracterísica }\end{array}$ & $\begin{array}{c}\text { Resultados } \\
\mathbf{( \% )}\end{array}$ & $\begin{array}{c}\text { Amostra especificada } \\
\text { no método }\end{array}$ \\
\hline $\begin{array}{c}\text { TAPPI } \\
\text { T211 }\end{array}$ & $525 \pm 25$ & $\begin{array}{c}\text { Até ser verificada a } \\
\text { ausência de pontos } \\
\text { pretos na amostra }\end{array}$ & $\begin{array}{c}\text { No mínimo } 1 \mathrm{~g} \\
\text { de amostra já } \\
\text { seca }\end{array}$ & $\begin{array}{c}4,97 / \\
7,91 / 11,70 / \\
12,48\end{array}$ & $\begin{array}{c}\text { Wood, pulp, paper and } \\
\text { paperboard (madeira, } \\
\text { celulose, papel e } \\
\text { papelão) }\end{array}$ \\
\hline $\begin{array}{c}\text { ASTM } \\
\text { D1762 }\end{array}$ & $750 \pm 5$ & $6 \mathrm{~h}$ & $\begin{array}{c}1 \mathrm{~g} \text { de amostra } \\
\text { úmida }\end{array}$ & 9,30 & $\begin{array}{c}\text { Wood Charcoal (carvão } \\
\text { de madeira) }\end{array}$ \\
\hline $\begin{array}{c}\text { ASTM } \\
\text { E1534 }\end{array}$ & 580 a 600 & $\begin{array}{c}\text { Até estabilizar o } \\
\text { peso da amostra }\end{array}$ & $\begin{array}{c}2 \mathrm{~g} \text { de amostra } \\
\text { úmida }\end{array}$ & 7,00 & $\begin{array}{c}\text { Particulate Wood Fuels } \\
\text { (combustíveis de } \\
\text { madeira particulados) }\end{array}$ \\
\hline $\begin{array}{c}\text { NBR } \\
8112\end{array}$ & $700 \pm 10$ & $\begin{array}{c}\text { Até ser verificada a } \\
\text { queima completa }\end{array}$ & $\begin{array}{c}1 \mathrm{~g} \text { de amostra } \\
\text { já seca }\end{array}$ & 4,32 & Carvão Vegetal \\
\hline
\end{tabular}

Primeiramente nota-se que nenhum dos métodos utilizados na bibliografia pesquisada é específico para palha de cana-de-açúcar. Devido à inexistência de método normatizado para tal material cada autor utilizou o método com o qual julgou que melhor se adequava a amostra. Os que utilizaram a TAPPI 211 consideraram a palha com um material celulósico semelhante à madeira, papel e polpa, enquanto os demais compararam com combustíveis derivados da madeira, como o carvão vegetal.

Ao analisar a Tabela 3 percebe-se que autores que utilizaram o método descrito na norma TAPPI 211 obtiveram resultados que diferiam entre si na faixa de 4,97\% - 12,48\%. Verifica-se que valores obtidos pelas metodologias ASTM D1762 e ASTM E1534 estão dentro da faixa obtida pelos autores que utilizaram a norma TAPPI 211, indicando que 0 método não é um dos fatores que causaram essa variação.

\section{CONSIDERAÇÕES FINAIS}

No presente trabalho analisou-se mais a fundo os resultados de diferentes bibliografias para o teor de cinzas presente na palha da cana-de-açúcar, no entanto ainda é necessário reproduzir esse estudo para as demais análises e resultados encontrados durante o 

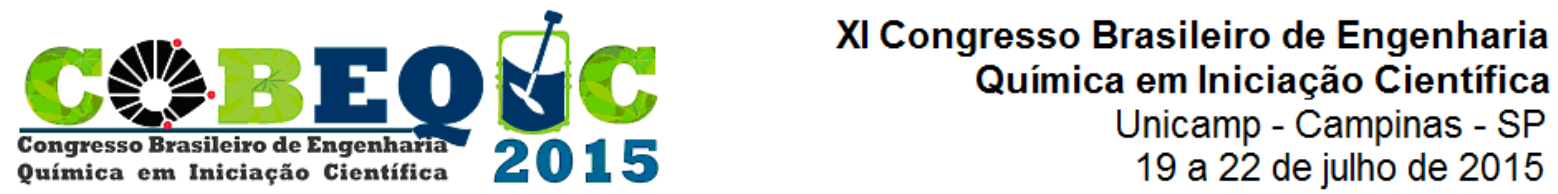

levantamento de dados para assegurar a palha de cana de açúcar como uma possível biomassa para a produção de biocombustíveis de segunda geração ou como combustível térmico.

\section{AGRADECIMENTOS}

A PRPG e ao CNPq pelo apoio financeiro na execução deste artigo.

\section{REFERÊNCIAS BIBLIOGRÁFICAS}

ALMEIDA, M.B.B. Bio-óleo a partir da pirólise rápida, térmica ou catalítica, da palha da cana-de-açúcar e seu co-processamento com gasóleo em craqueamento catalítico. Dissertação (Mestrado em Tecnologia de Processos Químicos e Bioquímicos) - Escola de Química, Escola de Química, Universidade Federal do Rio de Janeiro, Rio de Janeiro, 2008.

CARVALHO, DM. Caracterização físico-química e polpação etanol/soda do bagaço e da palha de cana-de-açúcar. Dissertação (Mestrado em Ciência Florestal) - Universidade Federal de Viçosa, Viçosa, 2012.

GEORGES, F. Caracterização da palha da cana-de-açúcar do rio grande do sul e de seus produtos de pirólise. Dissertação (Mestrado em Ciência dos Materiais) - Universidade Federal do Rio Grande do Sul, Porto Alegre, 2011.

MARABEZI, K. Estudo sistemático das reações envolvidas na determinação dos teores de lignina e holocelulose em amostras de bagaço e palha de cana-de-açúcar. Dissertação (Mestre em Ciencias Físico-Quimicas) - Instituto de Quimica de São Carlos, Universidade de São Paulo, São Carlos, 2009.

MIRANDA, I.C. Aproveitamento energético a partir de resíduos de biomassa: bagaço e palha de cana-de-açúcar. Dissertação (Mestrado em Tecnologia de Processos Químicos e Bioquímicos) - Escola de Química, Universidade Federal do Rio de Janeiro, Rio de Janeiro, 2009.

PAULA, L.E.R.; TRUGILHO, P.F.; NAPOLI, A; BIANCHI, M.L. Characterization of residues from plant biomass for use in energy generation. Cerne, Lavras, v.17, n.2, p.237-246, abr./jun. 2011.

PITARELO, A.P. Avaliação da susceptibilidade do bagaço e da palha de cana-de-açúcar à bioconversão via pré-tratamento a vapor e hidrólise enzimática. Dissertação (Mestrado em Química) - Universidade Federal do Paraná, Curitiba, 2007.

SEYE, O; CORTEZ, L.A.B.; GOMEZ, E.O. Estudo cinético da biomassa a partir de resultados termogravimétricos.. In: Encontro De Energia No Meio Rural, 3., 2000, Campinas. Proceedings online... Available from: 
XI Congresso Brasileiro de Engenharia Química em Iniciação Científica

$<$ http://www.proceedings.scielo.br/scielo.php?script=sci_arttext\&pid=MSC0000000022 000000200022\&lng=en\&nrm=abn>. Acesso em Dec. 2014.

SUÁREZ, J.A.; LUENGO, C.A.; FELFLI, F.F.; BEZZON, G; BEATÓN, P.A. Thermochemical Properties of Cuban Biomass. Energy Sources, Taylor \& Francis, 22:851-857, 2000. 